\title{
Rancang Bangun Aplikasi Pendeteksi Jenis Golongan Darah Berdasarkan Konsep Kepercayaan Rakyat Jepang (Minkan Shinkō)
}

\author{
Fahmi Candra Permana ${ }^{1}$, Ayung Candra Padmasari ${ }^{2}$, Sisilia Sylviani ${ }^{3}$ \\ 1,2) Program Studi Pendidikan Multimedia, Kampus UPI di Cibiru, \\ Universitas Pendidikan Indonesia \\ Jl. Raya Cibiru Km 15 Bandung 40393 \\ Email: 1fahmi.candrap@upi.edu, 2ayungcandra@upi.edu \\ 3) Departemen Matematika, FMIPA, Universitas Padjadjaran \\ Jl. Raya Bandung Sumedang KM.21, Kec. Jatinangor, Kabupaten Sumedang 45363 \\ Email: 3sisilia.sylviani@unpad.ac.id
}

\begin{abstract}
ABSTRAK
Ramalan golongan darah merupakan teknik peramalan yang dipercaya oleh leluhur orang jepang untuk memprediksi kepribadian seseorang, sifat alamaiah seseorang, ataupun kecocokan dalam memilih pasangan ideal bagi seseorang. Kepercayaan sebagian besar masyarakat Jepang kepada ramalan golongan darah adalah bukti betapa kuatnya konsep minkan shinkō atau kepercayaan rakyat tertanam di benak orang Jepang. Dalam penelitian ini dibangun suatu aplikasi yang dapat mendeteksi jenis golongan darah seseorang berdasarkan konsep kepercayaan rakyat jepang dengan menggunakan Artificial Intellegent menghitung bobot sejumlah pertanyaan yang mengacu pada konsep kepribadian maupun sifat alamiah seseorang. Penelitian ini membalik prediksi sifat seseorang berdasarkan golongan darah menjadi memprediksi golongan darah berdasarkan sifat seseorang. Aplikasi ini dibangun dengan menggunakan Bahasa Pemrograman Visual Basic dan menggunakan Artificial Intellegent dalam pembobotan jenis golongan darah seseorang.
\end{abstract}

Kata kunci: ramalan, minkan, shinkō

\begin{abstract}
Blood type divination is a divination technique that is believed by Japanese ancestors to predict a person's personality, a person's nature, or a match in choosing an ideal partner for someone. The belief of most Japanese people in the prediction of blood type is proof of how strong the concept of minkan shinkō or people's beliefs is embedded in the minds of Japanese people. In this research we build an application that can detect a person's blood type based on the concept of Japanese people's trust by using Artificial Intellegent to calculate the weight of a number of questions that refer to the concept of personality and the nature of a person. This research reverses the predictions of a person's nature based on blood type to predict blood type based on one's nature. This application is built using the Visual Basic Programming Language and uses Artificial Intellegent in weighting the type of a person's blood type.
\end{abstract}

Keywords: divination, minkan, shinkō

\section{Pendahuluan}

Perkembangan ilmu teknologi saat ini tidak serta merta menghilangkan dan menghapuskan beberapa konsep teori yang berlandaskan mitos ataupun kebudayaan beberapa etnis yang ada. Dalam penelitian ini kami tertarik untuk melakukan pembuktian dengan pendekatan saintifik, terkait hubungan antara ilmu sains dan teknologi dengan teori kebudayaan konsep kepercayaan rakyat Jepang (Minkan Shinkō) terkait dengan prediksi sifat alamiah seseorang berdasarkan jenis golongan darah.

Jepang dikenal sebagai negara maju dengan perkembangan ilmu sains teknologi dengan berjuta industri modern yang terkemuka di dunia. Namun di samping itu, masyarakat Jepang sendiri masih banyak yang percaya dengan ramalan, khususnya ramalan sifat seseorang berdasarkan golongan darah. Padahal ramalan sendiri hanyalah hasil dari memprediksi suatu hal tertentu tanpa adanya dasar yang jelas, maka dari itu sifatnya tidak ilmiah dan irasional (Goody, 1996:13). Sehingga hal tersebut berbanding terbalik dengan kemajuan yang ada, di mana seharusnya menuntut orang Jepang untuk berfikir lebih modern seiring dengan berkembangnya zaman. 
Di Jepang, ramalan golongan darah dipercaya dapat menjadi jembatan untuk lebih bisa menafsirkan karakter kepribadian seseorang dan sebagai pembuka jalan dalam berhubungan dengan orang lain (Dalby, 2007:247). Di Jepang, golongan darah berkonotasi pada sebuah konsep yang berbeda dari "golongan darah" dalam arti biologis. Sebagian besar masyarakat Jepang berorientasi kepada hubungan antara golongan darah dengan kepribadian, walaupun mereka hanya samar-samar mengerti mengenai benar atau tidaknya

hasil tersebut (Yoshino, 1992:31).

Banyak sekali publikasi buku-buku mengenai ramalan golongan darah pada paruh pertama tahun 1970an di Jepang. Kemudian majalah-majalah mulai memberikan informasi tentang ramalan berdasarkan tipe golongan darah dan hubungannya dalam berbagai aspek kehidupan sosial (Yoshino, 1992:31). Bahkan kuil di Jepang, ada yang menjual omikuji (merupakan secarik kertas ramalan yang didesain untuk mengutarakan keinginan akan nasib) golongan darah (Asian Lifestyle Design, 2012).

Pada dasarnya, Teknik ramalan berdasarkan golongan darah digunakan orang Jepang untuk meramalkan karakter seseorang. Teknik tersebut mulai dikenal luas oleh masyarakat Jepang dan mengalami puncak popularitasnya pada tahun 1980an. Namun ramalan golongan darah masih tetap digunakan hingga saat ini. Ada anggapan bahwa di Jepang hanya orang bodoh yang tidak mengetahui apa golongan darah mereka (Chaves, 2005:96). Meskipun tidak ada korelasi yang jelas antara ramalan golongan darah dengan kepribadian, tetapi hal tersebut begitu populer di Jepang.

Berdasarkan dari beberapa fakta terkait masyarakat Jepang yang notabene sudah modern dan memiliki teknologi yang maju dalam mengembangkan ilmu pengetahuan, tetapi masyarakatnya masih sangat percaya hal hal terkait ramalan (Minkan Shinkō) peneliti menjadi lebih tertarik untuk membangun suatu sistem aplikasi yang dapat digabungkan dengan ramalan kepercayaan masyarakat Jepang (Minkan Shinkō) mengenaik sifat seseorang berdasarkan golongan darah. Selain berpegang fakta terkait ramalan kepercayaan masyarakat Jepang (Minkan Shinkō), Peneliti juga telah membaca dari beberapa penelitian sebelunya terkait hubungan antara sifat seseorang terhadap jenis golongan darahnya.

Berikut beberapa penelitian yang menjadi acuan kami dalam melakukan penelitian ini, dan sudah dilakukan oleh peneliti lainnya terkait dengan hubungan jenis golongan darah dengan sifat atau perilaku alamiah seseorang, yang pertama adalah yang dilakukan oleh (Emaria, 2011) dari Universitas Sriwijaya dan telah terbit pada jurnal Generic Vol 6, No. 2, Tahun 2011 dengan Membuat Desain Alat Pendeteksi Golongan Darah Menggunakan Mikrokontroler, dari penelitian ini, kami menyimpulkan bahwa saat ini alat pendekti golongan darah sudah banyak dikembangkan bukan hanyak dari segi medis saja, melainkan dengan pendekatan teknologi informasi dan sistem komputer pun dapat dilakukan dengan baik, kemudian yang dilakukan oleh (Yanies, 2012) dari Universitas Airlangga dan telah terbit pada jurnal Japanology, Vol 1, No 1, Tahun 2012 dengan menganalisis Fenomena Ramalan Golongan Darah di Jepang Ditinjau dari Konsep Kepercayaan Rakyat (Minkan Shinkō), penelitian yang dilakukan oleh (Yanies, 2012) ini tidak ada kaitannya dengan bidang keilmuan kami, karena (Yanies, 2012) merupakan seorang budayawan yang meneliti kebudayaan jepang, tetapi justru inilah yang membuat kami lebih tertarik, karena (Yanies, 2012) menjelaskan bahwa sangat erat kaitannya masyarakat jepang dengan tingkat kepercayaannya pada ramalan golongan darah disana, sehingga peneliti mengambil beberapa fakta menarik terkait penelitian ini dari tulisannya (Yanies, 2012) ini, kemudian selain itu penelitian oleh (Eka, 2016) dari Universitas Cokroaminoto Palopo dan telah terbit pada jurnal Dinamika, Vol 7, No 1, Tahun 2016 yang melakukan Analisis Korelasi Antara Golongan Darah Tipe A, B, O dengan Modalitas dan Gaya Belajar Mahasiswa, dari tulisan ini kami mendapat kesimpulan bahwa berdasarkan studi lapangan dan beberapa percobaan langsung bahwa memang ada hubungan korelasi sifat atau cara belajar seseorang berdasarkan jenis golongan darahnya masing masing.

\section{Metode Penelitian}

Metodologi penelitian yang digunakan pada penelitian ini adalah dengan mengumpulkan beberapa studi literatur terkait sifat sifat seseorang berdasarkan jenis Golongan Darah, sebagai contoh dari beberapa sumber berikut adalah contoh deskripsi sifat alamiah sesuai dengan jenis golongan darahnya, 
- A: Type A persons are hard working, detail oriented and very organized.

- B: Type B's are known to go "my way" and are individualistic

- O: O's see the big picture and are dependable leaders

- AB: Due to the combination of A and B, they are considered to be difficult to read, yet creative.

Gambar 1. Deskripsi Singkat Sifat Seseorang Berdasarkan Golongan Darah.

Sumber : http://asianlifestyledesign.com/2010/04/japanese-blood-type-character-analysis/

Pada Gambar 1. Dijelaskan bahwa setiap orang, menurut kepercayaan orang jepang, memiliki sifat alamiah tersendiri berdsarkan setiap golongan darah, selain itu berdasarkan hasil riset diperoleh data sebagai berikut.

They say the majority of Japanese are type A. According to the Racial and Ethnic Distribution of Blood Types these are the breakdown of blood type percentages in various countries:

- Japanese : 38\% A, 22\% B, 30\% O and 10\% AB

- Chinese in Beijing: $27 \%$ A, 32\% B, 29\% O and 13\% AB

- Korean: $32 \%$ A, 31\% B, 28\% O and 10\% AB

- Vietnamese: $22 \% \mathrm{~A}, 30 \% \mathrm{~B}, 42 \% \mathrm{O}$ and $5 \% \mathrm{AB}$

- All USA: $42 \%$ A, $10 \%$ B, $42 \%$ O and $4 \%$ AB

- U. K.: $42 \%$ A, $8 \%$ B, $47 \%$ O and $3 \%$ AB

Gambar 2. Statistik Pengelompokan Jenis Golongan Darah di Beberapa Negara. Sumber : http://asianlifestyledesign.com/2010/04/japanese-blood-type-character-analysis/

Pada Gambar 2. Menunjukan bahwa di jepang sendiri mayoritas orang memiliki golongan darah A, hal ini dapat disimpulkan bawah orang jepang memiliki sifat keteraturan yang sangat tinggi, dan sangat obsesi untuk mencapai target sesuatu. Berikut beberpa ilustrasi sifat sifat seseorang berdasarkan jenis golongan darah.
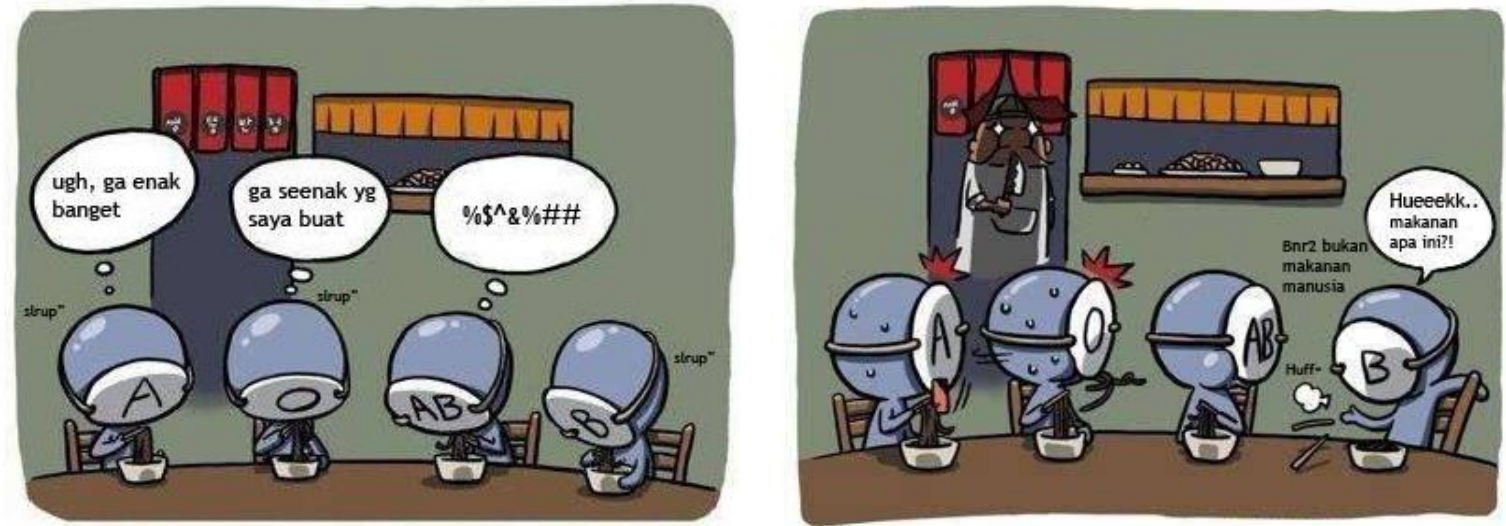

Gambar 3. Ilustrasi Karakteristik Tiap Golongan darah dalam suatu kasus Sumber : http://forum.detik.com/showthread.php?s=2b6803a04df839b5933b7f66eb9b2547\&t=59338 
Pada Gambar 3. Dijelaskan bahwa ketika mendapat suatu makanan yang tidak enak golongan darah A hanya berbicara pelan dengan komentar "ugh, ga enak banget" hal ini karena menurut teori kepercayaan orang jepang, mayaritas golongan darah A cenderung idealis namun masih bisa menjaga perasaan orang lain, golongan darah $\mathrm{O}$ berkomentar "ga seenak yang saya buat" cenderung multitasking dan multitalenta sehingga segala sesuatu bias dibandingkan dengan diri sendiri, gologan darah $\mathrm{AB}$ berkomentar “\%\$^\&\%\#” hal ini cenderung golongan darah $\mathrm{AB}$ lebih misterius dan sangat tertutup serta sangat sensitif dan selalu menjaga perasaan orang lain, berbeda jauh dengan golonga B dengan berkomentar "Hueeekkk.. makanan apa ini?!" hal ini menunjukan golongan darah B sangat terbuka, walaupun pikirannya hampir sama dengan sebagian orang, tetapi Golongan darah B tidak segan segan dalam mengungkapkan sesuatu.

Setelah mengumpulkan beberapa karakteristik sifat seseorang berdasarkan golongan darah, kemudian kami melakukan pengumpulan dan penyortiran beberapa sifat khas dari golongan darah tersebut, setelah itu kami menyusun pertanyaan pertanyaan untuk setiap golongan darah, dimana setiap pernyataan memiliki bobot hitung tersendiri pada setiap golongan dengan membagi tiga kategori jawaban untuk setiap soal, yaitu setiap user memilih jawaban "Ya" maka akan bernilai 2, jika memilih "kadang kadang" bernilai 1, sedangkan jika memilih "Tidak" maka akan bernilai 0 untuk setiap golongan darah tersebut, seperti terlampir pada Gambar 4

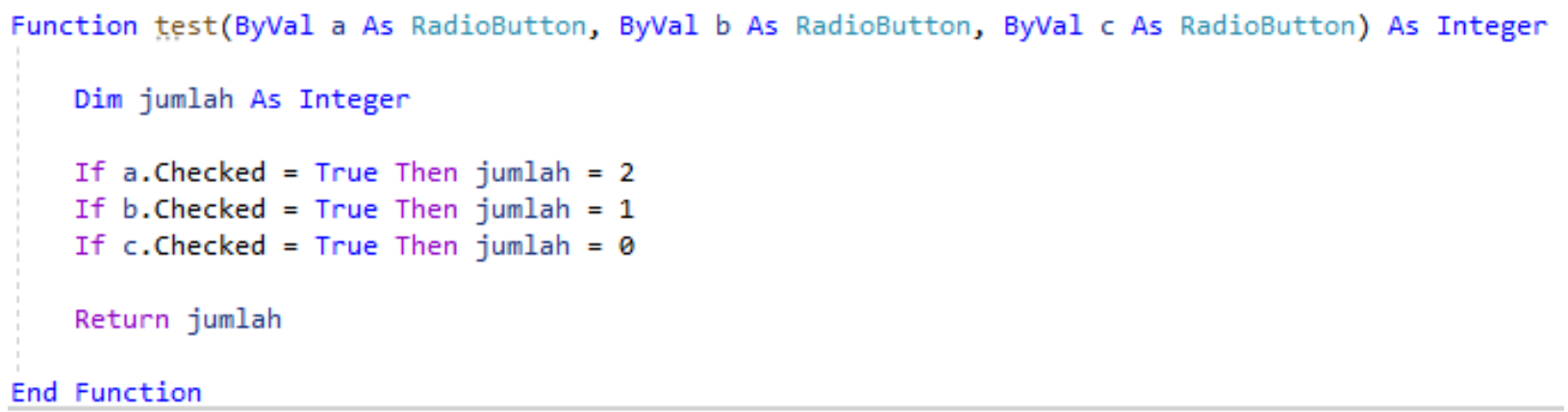

Gambar 4. Logika pembobotan setiap soal yang berpengaruh pada golongan darah.

Berikut beberapa contoh pertanyaan yang diberikan aplikasi terhadap user pada Gambar 5.

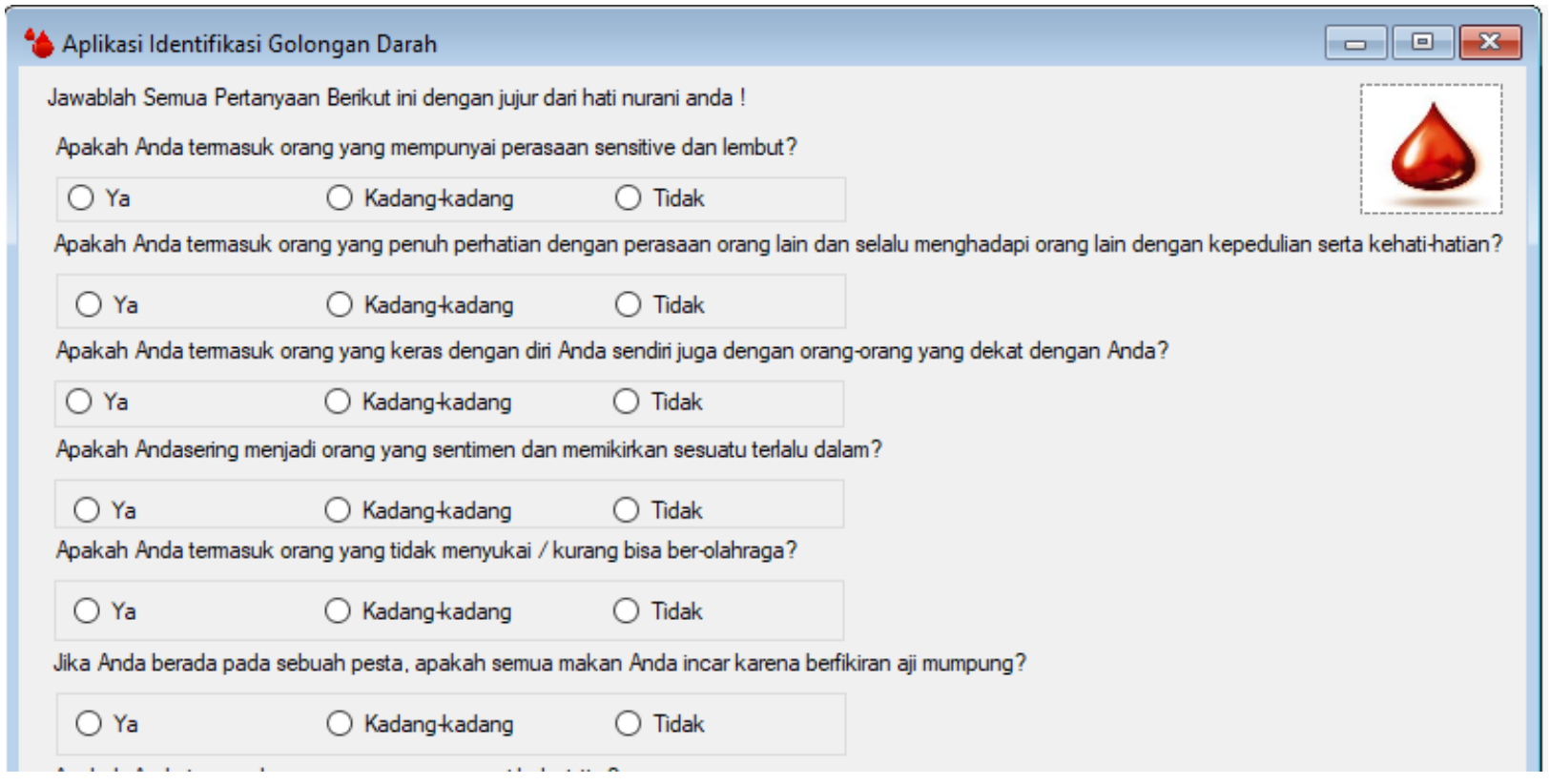

Gambar 5. Pertanyaan pada user terkait sifat sifat alamiah seseorang. 
Setelah user selesai membiri jawaban dari total 48 pertanyaan, aplikasi yang kami rancang dalam penelitian ini akan menghitung total keseluruhan bobot bagi setiap golongan darah, dimana jika memang banyak yang sesusai dengan sifat alamiah user, maka bobot itu akan berjumlah paling banyak dalam golongan darah tersebut, berikut proses perhitungan yang kami lakukan dalam penelitian ini.

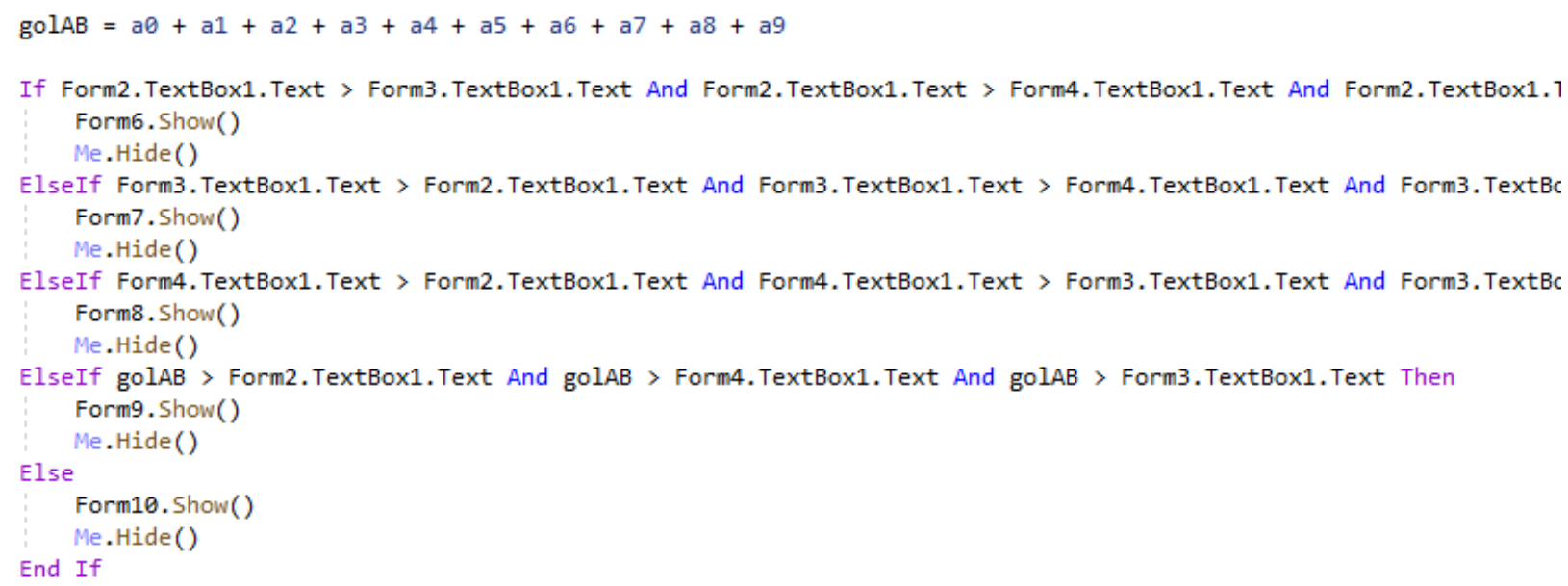

Gambar 6. Sekilas tentang proses perhitungan pembobotan untuk golongan darah $\mathrm{AB}$

Pada gambar 6. Ditunjukan bahwa jika golAB lebih besar dari golongan darah lainnya maka, aplikasi akan memprediksi bahwa user memiliki golongan dara AB.

\section{Hasil dan Pembahasan}

Hasil dari penelitian ini adalah suatu aplikasi berbasis Artificial Intellegent yang dapat memprediksi jenis golongan darah seseorang berdasarkan sifat dasar alamiahnya masing masing, karena yang kami lakukan adalah ingin melakukan pendekatan secara ilmiah terkait hubungan antara kepercayaan orang jepang tentang ramalan sifat alamiah seseorang dengan golongan darah nya masing masing.

Pada penelitan ini berhasil dibangun sebuah aplikasi menggunakan konsep Artificial Intellegent dengan menggunakan Bahasa pemrograman Visual Basic.net, berikut adalah hasil dari aplikasi yang kami bangun pada penelitian ini.

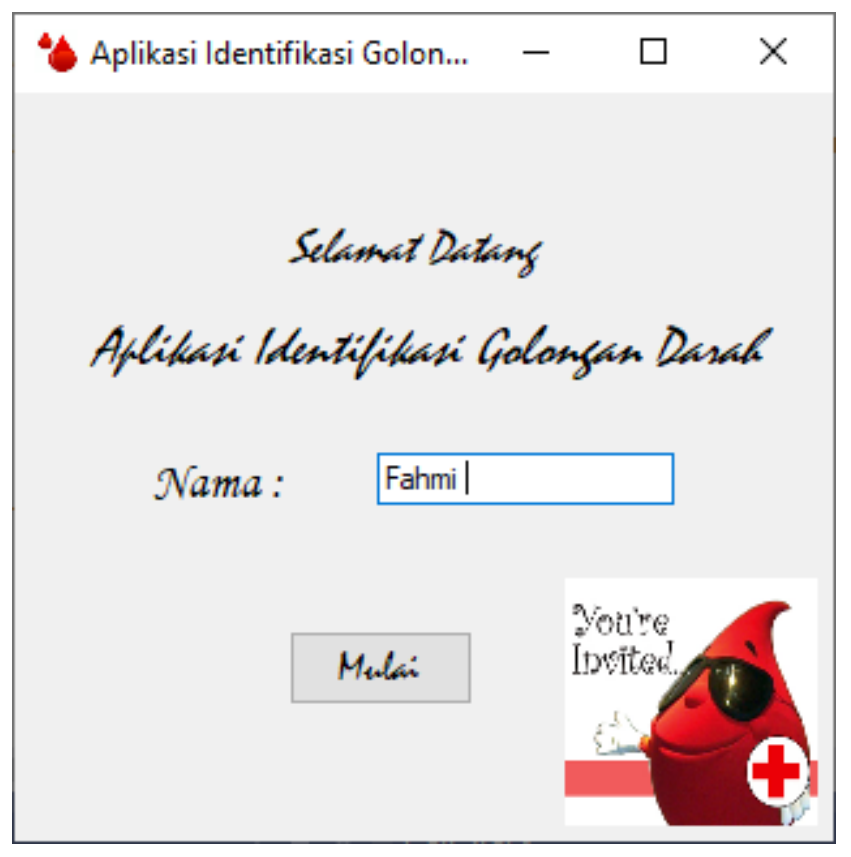

Gambar 7. Form Awal Login Aplikasi 
Pada form ini user diwajibkan untuk mengisi nama, agar kedepannya data user dapat disimpan dan dapat dianalisis dan divalidasi akurasi dari prediksi aplikasi yang kami bangun. Kemudian setelah mengisi nama, user diarah ke empat form yang berisi pertanyaan pertanyaan sebagai berikut.

Aplikasi Identifikasi Golongan Darah

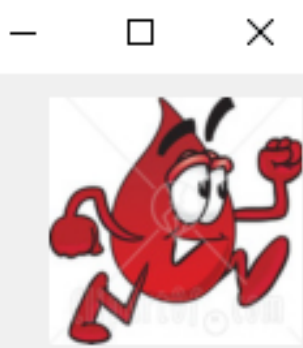

Jawablah Semua Pertanyaan Berikut ini dengan jujur dari hati nurani anda !

Apakah Anda termasuk orang yang susah menolerir kesalahan orang?

(C) Ya

Kadangkadang

Tidak

Apakah Anda termasuk orang yang mudah menabung?
Ya
Kadangkadang
Tidak

Apakah Anda termasuk orang yang sangat terorganisir?

$\bigcirc \mathrm{Ya}$

Kadangkadang

Tidak

Apakah Anda termasuk orang yang selalu konsisten?

$\bigcirc \mathrm{Ya}$

Kadangkadang

Tidak

Apakah Anda termasuk orang yang selalu tegas?
$\bigcirc \mathrm{Ya}$
Kadangkadang
Tidak

Apakah Anda termasuk orang yang keras kepala?

Ya

Kadangkadang

Tidak

Apakah Anda termasuk orang yang seorang yang perfeksionis?
Ya
Kadangkadang
Tidak

Apakah Anda termasuk orang yang mudah cemas?
Ya
Kadangkadang
Tidak

Apakah Anda termasuk orang yang keras terhadap orang-orang yang tidak sependapat dengan Anda?
Ya
Kadangkadang
Tidak

Apakah Anda termasuk orang yang senang bekerja sama dengan orang lain?
Ya
Kadangkadang
Tidak

Apakah menurut kamu, kamu sering kelihatan menyendiri dan jauh dari orang-orang?
Ya
Kadangkadang
Tidak

Apakah Anda merasa sebagai orang yang paling bisa dipercaya?
Ya
Kadang kadang
Tidak

Lanjut

Gambar 8. Contoh Daftar Pertanyaan yang harus dijawab User

User diminta untuk mengisi empat form yang berisi total 48 pertanyaan yang intinya setiap soal memiliki bobot khusus pada setiap golongan darah, setelah selesai pada setiap form, user diminta untuk klik lanjut agar bias sampai kepertanyaan selanjutnya. 
Setelah selesai mengisi empat form inti, user akan diminta untuk mengisi form terkahir, yang kami sebut ini adalah form validasi awal dimana disini kami meminimalisir terjadinya error atau kesalahan dalam mengisi jawaban, karena bagaimana pun juga menurut ilmu kedokteran setiap golongan darah orang tua dan anak itu pasti saling beraturan jadi kami tidak mungkin untuk mengabaikan eksepsi pada keilmuan yang sudah jelas sudah diakui dan divalidasi oleh ahli kedokteran. Oleh karena itu diakhir sesi sebelum mengeluarkan hasil prediksi dari aplikasi, kami memberikan form sebegai berikut kepadas user sesuai pada gambar 9 .

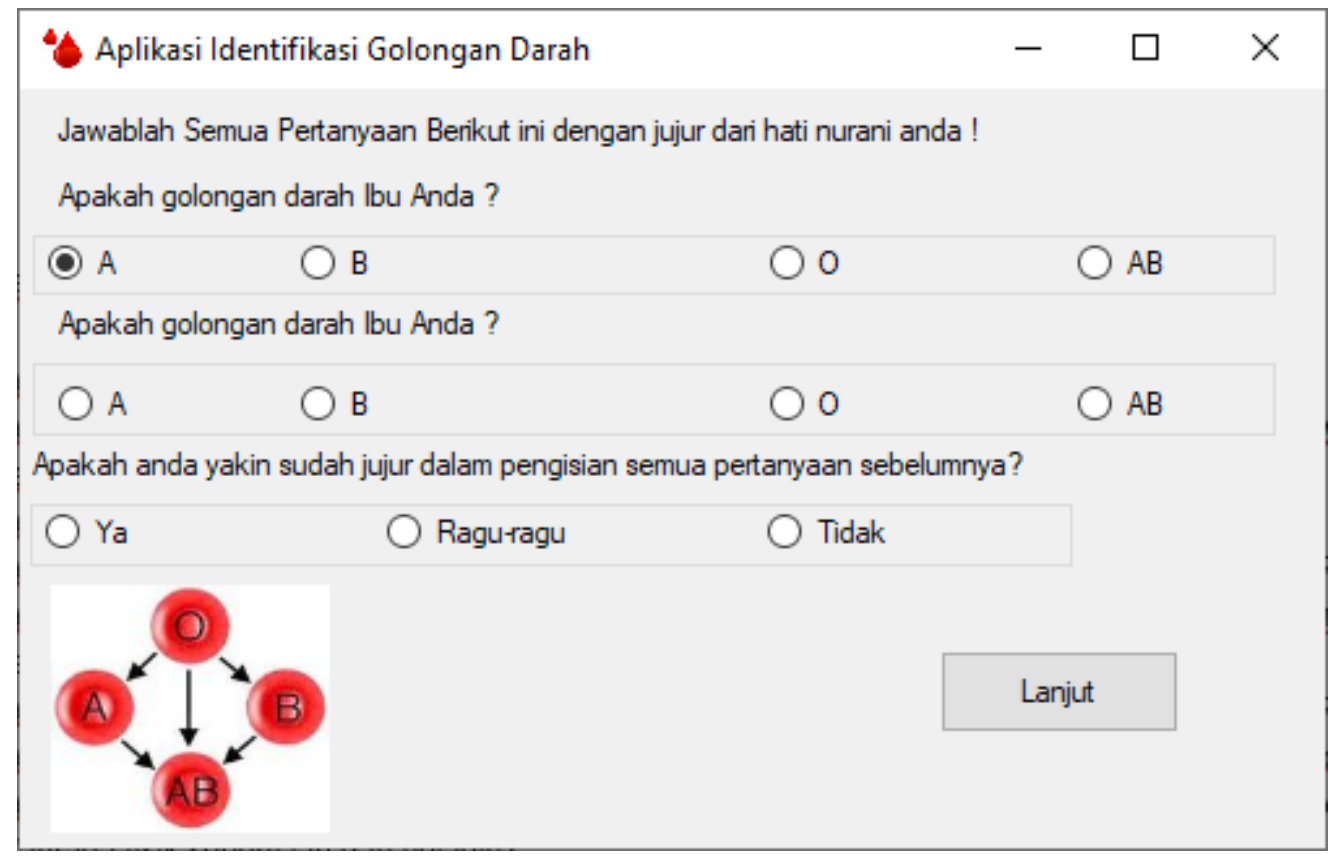

Gambar 9. Form validasi terkahir pada aplikasi.

Pada Gambar 9. Ditunjukan bahwa user diharuskan mengisi form terkahir ini dimana kami sebagai peneliti dari bidang keilmuan teknologi informasi tidak mungkin membuat program yang menyalahi aturan yang sudah jelas dan sudah dibuktikan dalam bidang keilmuan kedokteran, oleh karena itu kami memberikan form ini, agar hasil yang diberikan sesuai dengan aturan bahwa golongan darah ayah dan ibu itu akan sangat berpengaruh kepada anak. Berikut aturan yang menjadi acuan kami dalam membangun aplikasi prediksi golongan darah. Sesuia yang ada pada Tabel 1.

Tabel 1. Kemungkinan Golongan Darah Anak Berdasarkan Goldar Orangtua Sumber : https://id.theasianparent.com/golongan-darah-anak-pengaruhnya-ke-otak

\begin{tabular}{|c|c|c|c|}
\hline \multicolumn{2}{|c|}{ Golongan Darah } & \multicolumn{2}{c|}{ Anak } \\
\cline { 2 - 4 } Orang Tua & Mungkin & Tidak Mungkin \\
\hline A & A & A, O & B, AB \\
\hline A & B & A, B, AB, O & - \\
\hline A & AB & A, B, AB & O \\
\hline A & O & A, O & B, AB \\
\hline B & B & B,O & A, AB \\
\hline B & AB & A, B, AB & O \\
\hline B & O & B, O & A, AB \\
\hline AB & AB & A, B, AB & O \\
\hline AB & O & A, B & AB, O \\
\hline O & O & O & A, B, AB \\
\hline
\end{tabular}


Setelah mengisi semua form, maka hasil yang akan ditampilkan pada aplikasi ini adalah sebagai berikut.

Aplikasi Identifikasi Golongan Darah

\section{Fahmi}

$$
\text { Selamat Anda Mempunyai golongan Darah A }
$$

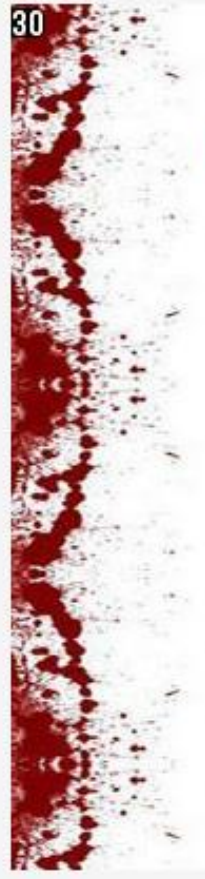

\section{Rahsia Personaliti Dari Genis Darah}

\section{Darah ' $\mathcal{A}$ '}

"Keharmonian dan keamanan adalah matfamat utama dalam hidup.

Gemar melakukan kerja-kerja secara berkumpulan dan mefibatkan diri dengan berpersatuan. Bijak bergauf dengan

individu disekelifing dan ternyata mereka juga sentiasa berasa senang untuk Gekerjasama. Sikap sensitif, sabar, dan bertimbang rasa yang ada dalam diri, itu melambangkan bahawa kamu tergolong dalam kategori individu yang memiliki keperibadian penyayang. Walau bagaimanapun ada kalanya kamu agak degil dan terlafu kuat bekerja sehinggakan tidak mengendahkan langsung waktu untuk Gerehat. Kamu harus ingat, kesihatan juga perfu diutamakan. Jangan kerana terfalu leka dengan kerja-kerja kamu itu, kesihatan diri pula yang terabai."

\section{Gambar 10. Hasil Prediksi Golongan darah}

Gambar 10. Menunjukan hasil golongan darah user setelah selesai menjawab seluruh rangkaian pertanyaan yang telah user isi, selain memberikan prediksi golongan darah, dalam aplikasi ini juga memberikan deskripsi khusus terkait sifat alamiah yang ada pada user sesuai dengan ramalan sifat seseorang berdasarkan golongan darah berdasarkan Konsep Kepercayaan Rakyat Jepang (Minkan Shinkō).

\section{Simpulan}

Dalam paper ini, disoroti hubungan dan kaitan antara ilmu pengetahuan berbasis teknologi dengan Konsep Kepercayaan Rakyat Jepang (Minkan Shinkō). Sehingga memunculkan ide yang membalik cara berpikir dari prediksi sifat berdasarkan golongan darah menjadi prediksi golongan darah setelah membaca sifat sifat yang ada pada diri seseorang. Dalam aplikasi ini pun berhasil dibangun sebuah system pendeteksi golongan darah yang berbasis Artificial Intellegent dengan menggunakan Bahasa Pemrograman Visual Basic .Net. 


\section{Daftar Pustaka}

1. Chavez, Amy. 2005. Guidebook To Japan: What The Other Guidebooks Won't Tell You. Ohio: Gom Press.

2. Dalby, Liza Crihfield. 2007. East Wind. Melts the Ice: A Memoir Through the Seasons. Berkeley and Los Angeles: University of California Press.

3. Goody, Jack. 1996. The East In The West. New York: Cambridge University Press.

4. Melati, Emaria. 2011. Desain dan Pembuatan Alat Pendeteksi Golongan Darah Menggunakan Mikrokontroler. Jurnal Generic, Vol 6, No 2, Juli 2011, pp. 48-54.

5. Permatasari, Yanies, 2013. Fenomena Ramalan Golongan Darah di Jepang Ditinjau dari Konsep Kepercayaan Rakyat (Minkan Shinkō). Jurnal Japanology Vol 1, No 1, Septemeber 2013, pp.66-77.

6. Tenriawaru, Eka Pratiwi, 2016. Analisis Korelasi Antara Golongan Darah Tipe A, B, O dengan Modalitas dan Gaya Belajar Mahasiswa. Jurnal Dinamika Vol 7, No 1, April 2016, pp. 41-49.

7. Yoshino, Kosaku. 1992. Cultural Nationalism in Contemporary Japan: A Sociological Enquiry. London: Routledge.

8. http://asianlifestyledesign.com/2010/04/japanese-blood-type-character-analysis/ diakses 26 Juni 2019

9. https://id.theasianparent.com/golongan-darah-anak-pengaruhnya-ke-otak diakses 26 Juni 2019

10. http: / / forum.detik.com/showthread.php? $s=2 b 6803 a 04 d f 839 b 5933 b 7 f 66 e b 9 b 2547 \& t=59338$ diakses 26 Juni 2019

11. https://id.theasianparent.com/karakter-anak-sesuai-golongan-darah diakses 26 Juni 2019 
